\title{
Conhecimentos, habilidades e atitudes: o conceito de competências no trabalho e seu uso no setor público
}

Aleksandra Pereira dos Santos

\section{Introdução}

O tema das competências no trabalho e nas organizações constitui importante categoria de estudos em comportamento organizacional, sobre a qual parece haver crescente interesse por parte das organizações e dos pesquisadores (BRANDÃo, 2009). De fato, o conceito de competência transformou-se em discurso para a necessidade de mudanças nas áreas de recursos humanos, sendo tomado como solução para diversos problemas: remuneração, capacitação e desempenho, entre outros.

De maneira geral, quando se fala do uso da abordagem de competências aplicada aos processos de gestão de recursos humanos - gestão por competências -, vive-se uma fase preliminar do modelo caracterizada, principalmente, pelo uso da abordagem em processos de seleção e desenvolvimento (BRANDÃO; GUImarães; Borges-Andrade, 2001. Bruno-Faria; Brandão, 2003). 
Ao realizarem análise sobre uso da noção de competência no setor público europeu, Hondeghem, Horton e Scheepers (2006) afirmam que o modelo permitiria gerir carreiras fundamentadas nos diferenciais dos seus servidores, abandonando-se a ideia de diplomas, exames ou antiguidade. Para as autoras, é a ausência de concorrência no setor público, ou sua existência menos explícita, que permite o emprego do conceito de competência de forma menos individualizada. Entretanto, não deixam de mencionar os problemas teóricos encontrados: a falta de clareza dos conceitos, a natureza prescritiva das teorias e a ausência de provas empíricas de sua eficácia.

Para além dessas críticas, a abordagem por competências - e sua prioridade no desenvolvimento e na flexibilidade - pode ser compatível com a dinâmica atual do mundo do trabalho, e substituir o modelo de qualificação tradicional, que parece não mais responder às demandas.

Com a publicação da obra Objetivo Competência, de Philippe Zarifian, o conceito de competências converge para a articulação com base em três dimensões: conhecimentos, habilidades e atitudes. O conhecimento corresponde a uma série de informações assimiladas e estruturadas pelo indivíduo, que lhe permite entender o mundo, ou seja, trata-se da dimensão do saber. A habilidade, por sua vez, está associada ao saber-fažer, ou seja, corresponde à capacidade de aplicar e fazer uso produtivo do conhecimento adquirido e utilizá-lo em uma ação com vista ao alcance de um propósito específico. Finalmente, a atitude é a dimensão do querer-saberfazer, que diz respeito aos aspectos sociais e afetivos relacionados ao trabalho. As três dimensões da competência estão interligadas e são interdependentes.

A noção de competência surge, portanto, com o desenvolvimento de capacidades que podem ser mobilizadas em situações, na maioria das vezes, pouco previsíveis, compatibilizando-se, portanto, com o conceito de evento, proposto por Zarifian (2001). O evento é caracterizado como o imprevisto e está relacionado a novos usos e processos que fazem parte da vida normal de uma organização. Logo, a base da abordagem de competência deixa de ser o desenho dos cargos e passa a ser o conceito dinâmico de habilidades e competências necessárias ao sucesso da organização e dos seus parceiros.

$\mathrm{Na}$ literatura é possível identificar autores que abordam a competência também como resultado ou efeito de tais qualificações aplicadas ao ambiente de trabalho. Le Boterf (1999) afirma que cada ação competente é produto de uma combinação de recursos, e que a competência reside no saber mobilizar e aplicar esses recursos.

Brandão (2009) aponta que, nos últimos anos, uma vertente integradora tem procurado definir a competência a partir de concepções provenientes de outras correntes. A competência passa a ser compreendida como conjunto de conhecimentos, habilidades e atitudes necessários à realização de uma atividade, mas também como comportamentos adotados no trabalho e realizações deste decorrentes. Tal definição aproxima a noção de competência à de desempenho.

Brandão e Guimarães (2001) tratam a competência como preditor do desempenho. Compreendem-no, de forma mais ampla, como resultado da articulação entre competência individual (conhecimentos, habilidades e atitudes mobilizados nas tarefas desempenhadas), características pessoais (idade, grau de instrução, motivação, estratégias de aprendizagem, etc.) e suporte recebido da organização (material e psicossocial). 
Observando-se a noção de desempenho voltado à tarefa, tal qual sugerido por Sonnentag e Frese (2002), podemos novamente aproximar os construtos "desempenho" e "competências". Para os autores, esse desempenho refere-se à capacidade de o indivíduo desenvolver atividades que contribuam com a organização, seja de forma direta - como ocorre em áreas finalísticas - ou indireta - como se observa em áreas de coordenação ou suporte.

É diante da diversidade de conceitos sobre o tema que este artigo se propõe por meio de duas revisões teóricas - avaliar as principais características da produção nacional e a discutir os conceitos de competências em publicações, cujo foco é o setor público. Para tanto, o documento encontrase dividido em três seções: a primeira enfoca a metodologia empregada nas revisões; a segunda trata dos resultados e da discussão; e, ao final, serão apresentadas convergências e lacunas das produções analisadas.

\section{Método}

Para a revisão da produção nacional, foi realizada pesquisa em periódicos das áreas de Administração e Psicologia. A escolha dos periódicos observou o trabalho realizado por Borges-Andrade e Meira (2003), no qual foram considerados critérios como a necessidade de indexação do periódico e a avaliação satisfatória no Sistema Qualis da Coordenação de Aperfeiçoamento de Pessoal (Capes) do Ministério da Educação. Os periódicos analisados estão dispostos na Tabela 1.

\section{Tabela 1 - Periódicos nacionais revisados}

\begin{tabular}{l|l}
\hline Área do Conhecimento & Periódico \\
\hline & Revista Brasileira de Administração Pública (RAP) \\
Revista de Administração de Empresas (RAE) \\
RAE - Eletrônica \\
Revista de Administração Contemporânea (RAC) \\
Revista de Administração Mackenzie \\
& Revista de Administração da Universidade de São Paulo (USP) \\
& Revista de Gestão da USP \\
& Revista Eletrônica de Administração (Read) \\
& Organização e Sociedade (UFBA) \\
\hline \multirow{5}{*}{ Psicologia } & Comportamento Organizacional e Gestão \\
& Estudos de Psicologia (Natal) \\
& Psicologia: Reflexão e Crítica \\
& Psicologia em Estudo \\
& Estudos de Psicologia (Campinas) \\
& Psicologia: Teoria e Pesquisa \\
& Psicologia Ciência \& Profissão \\
& Psicologia e Sociedade \\
& Revista Psicologia: Organizações e Trabalho - rPOT \\
& Psico USF \\
& Psico PUC \\
& Psicologia em Estudo \\
\hline
\end{tabular}

Fonte: Elaborado pelo autor 
Ressalta-se que o período de análise se estendeu de 2007 a 2010, por duas razões: o marco conceitual do tema das competências na administração pública brasileira é o ano de 2006, com a edição do Decreto n $\mathrm{n}^{\circ}$.707; e extensa revisão nacional e estrangeira sobre o tema foi realizada por Brandão (2009), de 1996 a 2006. Dessa forma, as conclusões gerais apresentadas pelo autor servirão de referencial comparativo para as publicações, conforme período em análise.

Para a revisão do construto das competências em publicações, cujo foco é o setor público, foram analisados ensaios teóricos e relatos de pesquisa publicados entre 2000 e 2010, em periódicos editados no Brasil e no exterior. Os periódicos utilizados foram os dispostos na Tabela 1, com a inclusão da Revista do Serviço Público da Escola Nacional de Administração Pública (ENAP).

Para a coleta de ensaios ou relatos de pesquisa em periódicos estrangeiros, foram usadas as bases de dados: SAGE, Journals on Line, Emerald e Scientific Eletronic Library on Line (Scielo). A busca se deu por palavrachave que correspondesse à(s) competência(s), competência(s) no trabalho, gestão por competências. Em razão do objetivo do estudo e do seu foco no setor público, também foram incluídos os periódicos estrangeiros dispostos na Tabela 2.

Quanto ao critério de análise, o termo "setor público" foi utilizado em sentido subjetivo, conforme definido por Di Pietro (2002). De acordo com o autor, é possível definir administração pública como sendo o conjunto de órgãos e de pessoas jurídicas aos quais a lei atribui o exercício da função administrativa do Estado, independentemente da sua natureza jurídica ou regime de funcionamento.

\section{Resultados e discussão}

Os resultados serão apresentados e discutidos da seguinte forma: inicialmente aqueles oriundos da análise da produção científica nacional; em seguida, a apresentação do conceito e sua utilização no setor público.

\section{Produção Nacional}

As 14 pesquisas foram analisadas e classificadas, considerando aspectos apontados por Borges-Andrade e Meira (2003)

Tabela 2: Periódicos estrangeiros revisados

\begin{tabular}{l|l}
\hline Área do Conhecimento & Periódico \\
\hline & Revue Française de Gestion \\
& Revue Française de Administration Publique \\
Revista Iberoamericana de Administração Pública & Public Personnel Management \\
Administração Pública & Public Performance Management Review \\
& Public Administration Review \\
& International Journal of Public Sector Management \\
& International Journal of Public Administration. \\
\hline
\end{tabular}

Fonte: Elaborado pelo autor 
no que se refere aos fundamentos da pesquisa, seus objetivos e resultados. Entre os aspectos, encontram-se: área de publicação, enfoques teóricos utilizados, instrumentos de coleta de dados, entre outros que permitissem caracterizar a produção sobre o tema.

No que se refere à área de publicação do periódico e à vinculação dos autores, um artigo foi publicado em revista da área da Psicologia; os demais se concentraram na área da Administração, com destaque para os periódicos: Revista de Administração Pública (RAP), Revista de Administração Mackenzie (RAM) e Revista de Administração da Universidade de São Paulo (RAUSP). Quanto à titulação indicada pelos autores e coautores, dezoito eram da área da Administração, dez de Psicologia e seis de outras áreas do conhecimento, aqui identificadas: Educação, Engenharia, Ciência da Informação, Ciência da Saúde e Contabilidade. Quanto aos vínculos dos autores e coautores, é possível perceber maior dispersão em relação às instituições, com predominância discreta para a Universidade de Brasília (UnB), a Universidade de São Paulo (USP) e a Fundação Getúlio Vargas (FGV).

Também é frequente a produção de trabalhos com autores de diferentes áreas do conhecimento: Psicologia e Administração; Administração e Educação ou Engenharia; e Psicologia e Educação. Porém, não é possível falar em quantidade predominante de parcerias entre os autores de Psicologia e Administração, tal como verificado por Brandão (2009); nem do equilíbrio, no período em análise, em periódicos dessas duas áreas do conhecimento. Essa constatação pode ser atribuída pelo surgimento e expansão de outras áreas a tratarem do tema das competências no trabalho e nas organizações, bem como pelo crescimento de publicações em periódicos de Administração, conforme apresentado inicialmente.

No que se refere aos objetivos dos estudos, são maioria os que tratam da identificação de competências necessárias a determinadas funções, conforme descrito na revisão nacional de Brandão (2009). Esses estudos tomam por base a análise de papéis ocupacionais ou funções, como:
“(...) a pluralidade metodológica nos estudos sobre o tema das competências reflete-se, inclusive, no uso das mais diversas análises, com destaque para métodos de interdependências nas pesquisas, com inclusão de variáveis associadas ao contexto(...)” gerentes, contadores, profissionais da informação, etc.

Cardoso e outros (2009) buscaram desenvolver e validar estatisticamente uma escala de competências para o "contador". A identificação e descrição das competências requeridas foram realizadas nas seguintes etapas: a) análise da fundamentação teórica sobre competências no âmbito da área comportamental; b) preparação de 
variáveis ou itens a serem mensurados a partir da análise das competências citadas por outros estudos, cujo foco era os profissionais de contabilidade; c) agregação das competências identificadas de acordo com o cargo em questão; d) construção do significado de cada competência no instrumento, objetivando a redução dos erros de interpretação por parte dos respondentes; e) realização de duas etapas de validação teórica; e f) validação semântica ou pré-teste aplicado em 14 profissionais constituintes da população. Dessa forma, foram descritas 18 competências e o questionário foi submetido a 159 profissionais.

Outro relato sobre identificação de competências é o de Campos e outros (2008), que apresenta uma lista de 21 habilidades e atitudes extraídas da literatura, associando-as à ideia de empregabilidade, entre elas estão: administração de conflitos, autodesenvolvimento, comprometimento, interesse, comunicação escrita, comunicação verbal, ética, seriedade, custos, organização, planejamento, proatividade e relacionamento interpessoal. O questionário foi aplicado a 156 gestores de recursos humanos em diversos ramos de atividade. Para tanto, foi utilizada uma escala Likert de 1 a 5, relativa ao grau de importância das habilidades e atitudes para a organização.

No que se refere aos objetivos, cinco dos 14 relatos podem ser classificados enquanto pesquisas que buscam avaliar os modelos relativos à gestão por competências implantados em organizações ou os instrumentos desenvolvidos para identificação de necessidades de competências. Nesse caso, os relatos procuraram: a) identificar efeitos nas relações entre trabalhadores, após a introdução da gestão por competência (AMARO, 2008); b) apontar elementos que dificultam o modelo relativo à gestão por competências (APPEL; BitTencourt, 2008); c) identificar a percepção de sujeitos quanto a instrumentos de avaliação por competências (BRANDÃo et al., 2008. DE SORDI; AZEVEDO, 2008); e d) analisar o entendimento dos dirigentes quanto ao conceito de competências e ao modelo relativo à gestão por competências (CASSANDre; ENDrICHI; VERCESI, 2008).

Amaro (2008) propõe-se a discutir os efeitos da introdução da noção de competências nas relações entre trabalhadores e empresa, com base nas modificações e nas dimensões conceitual, social e experimental da qualificação. Para isso, realizou um estudo de caso na área de manutenção de locomotivas de uma grande empresa de mineração e logística. Os temas e as categorias foram os seguintes: a) dimensão conceitual que se subdivide em: conhecimentos gerais e específicos; treinamento e formação profissional; diplomas e certificados; b) dimensão social que se subdivide em: plano de cargos e salários; sistema de remuneração; carreira; empregabilidade; sindicato; e c) dimensão experimental que se subdivide em: saber-fazer (procedimentos empíricos, esquemas, habilidades, modelos mentais, algoritmos e representações) e saber-ser (aptidão, inteligência, capacidades, vontade, responsabilidade, atitudes, visão de mundo e valores). $\mathrm{O}$ estudo revela que os usos da noção de competência na gerência tendem a individualizar as relações entre trabalhadores e empresa, a partir do enfraquecimento das dimensões conceituais e sociais da qualificação.

Por fim, três relatos de pesquisa têm como objetivo examinar a relação entre a expressão de competências e variáveis contextuais (BRANDÃO; BAHRY; FreITAS, 2008. SANT'ANNA, 2008) ou a mobilização de competências em contextos 
organizacionais (BAHRY; TOLFO, 2007). Brandão e outros (2008) verificaram a relação preditiva acerca do suporte à transferência de aprendizagem (variável de nível organizacional) e a aplicação de competências desenvolvidas em cursos de pós-graduação stricto sensu.

De forma análoga, Sant'anna (2008) analisou a relação entre uma variável organizacional - modernidade organizacional - e o grau de demanda de competências individuais. Seus resultados apontam para uma relação inversa entre a demanda de competências e os graus de modernidade, caracterizados pela evolução de políticas e práticas organizacionais. Já Bahry e Tolfo (2007), ao investigarem a percepção de empregados quanto à mobilização de competências no trabalho, demonstraram não apenas a favorável mobilização dessas competências, mas também a existência de fatores que influenciam a intensidade dessa mobilização, tais como: suporte e organização, tipo de atividade exercida e relação entre as atividades com a formação dos sujeitos.

A lacuna de investigações acerca da relação entre competências e variáveis de contexto em estudos nacionais foi previamente apontada por Brandão (2009). De fato, a representação desses estudos ainda é modesta, em especial quando comparados aos estudos que tratam da identificação de competências.

Quanto à natureza da pesquisa, os relatos utilizaram, em sua maioria, abordagem qualitativa e combinação qualitativaquantitativa. Há discreta predominância das abordagens qualitativas nos estudos sobre a avaliação do modelo relacionado à gestão por competências. Em duas pesquisas, métodos qualitativos foram utilizados para identificação de competências profissionais (Mello et al., 2007; Miranda, 2008). Cabe destacar a descrição de competências relevantes para um empreendedor de sucesso, que, a partir de narrativas e entrevistas de um empresário disponíveis na internet, constituiu-se corpus da pesquisa. Os estudos de natureza qualitativa-quantitativa, conforme já previsto por Brandão (2009), utilizam métodos qualitativos, tais como entrevistas e análises de conteúdo, para a elaboração de instrumentos posteriormente analisados quantitativamente. Nos estudos quantitativos, a ênfase se dá na aplicação de instrumentos já existentes ou daqueles cuja construção se deu com base na literatura.

De forma semelhante à revisão realizada por Brandão (2009), no caso de pesquisa qualitativa, a área predominante dos autores é Administração e, no caso de pesquisas de natureza qualitativa-quantitativa, há uma autoria conjunta de profissionais das áreas de administração e psicologia, o que propicia a pluralidade metodológica ressaltada pelo autor. Por outro lado, nos estudos de natureza quantitativa, não foi possível diagnosticar a dominância de autoria, uma vez que apenas três relatos tiveram pesquisa dessa natureza, e seus autores foram de áreas distintas.

Quanto à natureza do estudo, dez estudos relatavam pesquisa com desenho e utilizavam o survey como desenho de investigação. Os demais artigos eram relatos de experiência, e nenhum deles utilizou desenho experimental ou pesquisa-ação.

Quanto aos instrumentos e procedimentos de análise utilizados, oito pesquisas utilizaram questionários semiestruturados e estruturados ou escalas. Tais instrumentos tinham como principal finalidade identificar a mobilização de competências adquiridas ou o grau de necessidade de competências profissionais. Além de instrumentos específicos de mensuração de competências, também foram utilizados os 
seguintes questionários ou escalas: suporte à transferência de aprendizagem (BRANDÃO et al., 2008); percepção de avaliação de desempenho (BRANDÃo et al., 2008); avaliação do modelo de gestão por competências (CASSANDRE et al., 2008); modernidade organizacional (SANT'ANNA, 2008).

Quatro estudos combinaram a análise de documentos e a realização de entrevistas estruturadas ou semiestruturadas. Dois estudos utilizaram testes com objetivo de avaliar competências (DE Sordi; AzEvedo, 2008. De Sordi et al., 2009). A observação também foi utilizada em dois estudos com suporte de outros instrumentos - análise de documentos e entrevistas -, para identificação de competências relevantes aos profissionais da área $\mathrm{da}$ informação (Amaral, 2009; Miranda, 2008). A análise de documentos foi utilizada isoladamente em apenas uma pesquisa (Mello et al., 2007). É confirmada, assim, a pluralidade metodológica nos estudos sobre o tema, já apontada por Brandão (2009).

Os procedimentos de análise dos dados estão relacionados aos instrumentos de pesquisa utilizados. Assim, nas pesquisas com utilização de documentos, entrevistas, questionários semiestruturados e observação, foram utilizados métodos de análise de conteúdo. Todas as pesquisas que utilizam questionários fechados ou escalas relatam o uso de análises descritivas. Quatro estudos também utilizaram análise fatorial exploratória com objetivo de identificar dimensões subjacentes às escalas aplicadas (BRANDÃo et al., 2008. BRANDÃO; Bahry; Freitas, 2008. Cardoso et al., 2009. SANT'ANNA, 2008). Foram utilizadas ainda: análise de variância e regressão múltipla com objetivos, respectivamente, de traçar comparação entre grupos e identificar relações de predição entre variáveis de estudos; modelagem por equações estru- turais, combinando-se técnicas de interdependência para dar suporte a sugestões de relações causais; e estatísticas não paramétricas, para análise de variáveis categóricas.

Dessa forma, a pluralidade metodológica nos estudos sobre o tema das competências reflete-se, inclusive, no uso das mais diversas análises, com destaque para métodos de interdependências nas pesquisas, com inclusão de variáveis associadas ao contexto, tais como suporte à aprendizagem e modernidade organizacional e suas relações com a variável competência.

Em todas as pesquisas, os dados tiveram origem primária. Quanto ao segmento da economia estudado, doze estudos concentraram-se no setor terciário (serviços), e apenas dois tiveram como foco o setor secundário (AMARO, 2008; CASSANDre et al., 2008). Nove estudos trataram de pesquisa no setor privado, e quatro trataram de organizações públicas. Destes, três investigaram empresas públicas (BAHRY; TOLFO, 2007. Brandẽo; Bahry; Freitas, 2008. BRANDÃo et al., 2008;) e uma organização do Poder Judiciário (Appel; Bittencourt, 2008). Houve, portanto, uma diminuição de estudos empíricos cujo setor de análise é o público, contrariamente ao diagnosticado por Brandão (2009). Não foram encontrados artigos cuja análise se dava em organizações públicas constituintes da administração direta (ministérios) ou em autarquias e fundações. Nenhum artigo relatou estudo em organizações do terceiro setor.

No que se refere à noção de competência ou às correntes teóricas adotadas, cinco estudos assumiram a competência enquanto comportamentos observáveis no trabalho (BRANDÃo et al., 2008), descrevendo-as, quando necessário, sob a forma de referenciais de desempenho (AMARAL, 
2009; Cardoso et al.; 2009; Mello et al., 2007; Miranda, 2008). Além das descrições de comportamento, Mello e outros (2007) listaram características ou traços individuais de um empreendedor de sucesso. Para os autores, a competência pode ser percebida como uma característica que engloba diferentes traços de personalidade, habilidades e conhecimento, influenciados por experiência, capacitação, educação, história familiar e aspectos demográficos peculiares à pessoa.

Quatro pesquisas utilizaram a abordagem francesa da concepção de competência e, portanto, associam-na ao contexto de trabalho (CAmpos et al., 2008. CASSANDRE et al., 2008. De Sordi; Azevedo, 2008. De SORDI et al., 2009). Outros cinco artigos adotaram concepção integradora da noção de competência apontada por Brandão (2009). Neles, a noção de competência refere-se não só ao repertório de conhecimentos, habilidades e atitudes que um indivíduo possui, ou à sua formação específica, mas também ao desempenho ou ação manifestos no trabalho. Appel e Bittencourt (2008) destacam a diversidade de ênfases sobre o tema das competências, porém percebem e adotam a convergência no sentido de a competência buscar desenvolvimento pessoal e profissional que leve a melhor desempenho ou resultado no trabalho.

\section{Produção nacional e estrangeira}

Nessa seção analisam-se as noções de competências no trabalho adotadas em 24 documentos selecionados, entre ensaios e relatos de pesquisa empírica. Destes, nove são produções nacionais e 15 produções estrangeiras. Os ensaios teóricos versam sobre a noção de competências no trabalho, o uso e a aplicabilidade do conceito no setor público. Os relatos de pesquisa empírica tratam da identificação de competências profissionais, bem como do diagnóstico de necessidades de treinamento, ou ainda, das relações entre as competências profissionais, a aprendizagem e o desempenho.

No que se refere à produção nacional, o conceito de competência, enquanto tríade formada por conhecimentos, habilidades e atitudes, englobando não só questões técnicas, mas também aspectos sociais e afetivos relacionados ao trabalho, é apre-

“Ao apresentar os diversos conceitos sobre competências no trabalbo, este estudo conclui que os documentos analisados remetem à convergência do conceito de competência, diante da complexidade e fragmentação teórica previamente constatadas na literatura."

sentado por Ribeiro, Guimarães e Souza (2002), Bruno-Faria e Brandão (2003) e Bahry e Tolfo (2007). Tal conceito associa a competência a um conjunto de insumos conhecimentos, habilidades e atitudes necessários ao desempenho eficiente de indivíduos. Os autores defendem que não é possível um conjunto de tarefas predefinidas e estáticas, mas, sim, novas respon- 
sabilidades frente a situações de trabalho complexas, acompanhadas da permanente reflexividade no trabalho.

É a indicação de que competências são reveladas quando as pessoas agem em situações profissionais com as quais se deparam, apresentada por Zarifian (2001), que complementa as noções de competências utilizadas por Brandão e outros (2008), Brandão, Bahry e Freitas (2008). A essa noção de competência, é agregada a noção de desempenho e a expressão das competências em equipes ou na organização como um todo, conforme destacam os estudos de Bruno-Faria e Brandão (2003) e Brandão e outros (2008).

Quando se trata de segmentos profissionais da área da saúde, o conceito de competência adotado também se refere a uma concepção dialogada que aborda o desenvolvimento de capacidades ou atributos, sejam estes intelectuais, psicomotores e/ou afetivos que, quando articulados, resultam em distintas maneiras de realizar, com sucesso, as ações essenciais de uma determinada prática profissional. O conceito também converge para o de Zarifian (2001), que admite a noção de competência não só como uma instrumentalização de saberes e capacidades, mas também como a mobilização desse repertório em determinado contexto, caracterizando a competência como o saber agir em determinada situação (Perrenoud, 1999; Saupe et al., 2007).

Por fim, quanto aos estudos nacionais, cabe ressaltar que, nos moldes delimitados no método deste estudo, todos os documentos encontrados referem-se a relatos de pesquisa empírica realizados em segmentos específicos do setor público, aqui tratados enquanto segmentos profissionais, quer de empregados públicos e servidores públicos de governos estaduais quer de profissionais da saúde. Não foram encontrados relatos de pesquisa ou ensaios, nos moldes delimitados no método deste estudo, sobre segmentos da administração pública federal. Pode-se sugerir não só a lacuna de discussão do construto das competências no trabalho e seu uso, mas também a carência de pesquisas empíricas nesse segmento.

No que se refere às publicações estrangeiras, cabe destacar Horton (2000), cujo ensaio trata das origens do conceito competência e seu impacto no setor público. A autora traça uma evolução da organização do trabalho no setor público, cujo foco evoluiu de um conjunto de diferentes ocupações agrupadas por conhecimentos e habilidades, requeridos para a investigação de fatores, que incluíam características pessoais, motivação e demais atributos geradores do desempenho diferenciado. Em seu estudo, a autora apresenta as diferenças entre o conceito de competência utilizado no serviço público dos Estados Unidos e do Reino Unido. No caso britânico, a noção de competência está diretamente relacionada à noção de desempenho; correspondendo, portanto, às ações, aos comportamentos e aos resultados que uma pessoa deveria demonstrar (HORTON, 2000). Refere-se, nesse caso, ao que é realmente requerido como desempenho no trabalho e está relacionado ao termo competence.

A noção do serviço público norteamericano aproxima-se do conjunto de habilidades, atitudes e talentos necessários ao trabalho e que tornam a performance no trabalho satisfatória ou excepcional. Refere-se ao que é requerido ao indivíduo e está relacionado ao termo competency. Tal noção também é defendida por Nalbandian e Nalbandian (2003), que acrescentam a esse sentido a noção de contexto, desenvolvimento e interdependência. No que se 
refere à existência de duas abordagens do construto das competências no trabalho, Farnhan e Stevens (2000) reforçam os argumentos de Horton (2000), resumindoos em um foco externo - representado pelo desempenho - e um foco interno $\mathrm{o}$ indivíduo.

Young e Dulewicz (2003) ressaltam a distinção entre os dois conceitos e apresentam uma abordagem integradora entre competency e competence, cujo foco é o desempenho ou a performance, conforme demonstrado na Figura 1. Nela as características individuais e comportamentais - tais como conhecimentos, motivação e habilidades agregam-se às atividades necessárias ao exercício adequado de determinada função ou trabalho.

É, portanto, o modelo integrado de competência no papel de conhecimentos, habilidades e atitudes, que uma pessoa possui para trabalhar bem e contribuir para a performance da organização, o que possui maior aceitação - forma análoga às publicações brasileiras -, sendo compartilhado por Hondeghem e Vandermeulen (2000), Bhatta (2001) e Bhatta (2002), Bourgault (2005), Nanquin e Holton
(2006), Faria e Alizo (2006), Noraida e Mineira (2007) e Gretha-Taylor (2008). O último autor apresenta conceito de competência distinto do tradicional - conhecimentos, habilidades e atitudes -, ao defender que a competência tem foco no futuro e no desempenho, além de incluir traços, motivações e comportamentos que interferem nesse desempenho.

Aliado à noção de competência na qualidade de atributos do indivíduo, Virtanen (2000) refere-se à competência como um tipo de capital ou recurso humano que pode ser transformado em produtividade. Tal conceito, segundo o autor, é diferente do termo "qualificação", entendido como requisitos de certo conjunto de tarefas.

Ao traçar um panorama dos modelos relativos à gestão por competências na Europa, Hondeghem e outros (2006) defendem que as interpretações e definições de competências e gestão por competências são tão numerosas quanto diferentes entre si; mas compreendem, do ponto de vista semântico, as palavras "competição" e "competência" como similares. Para as autoras, a concorrência

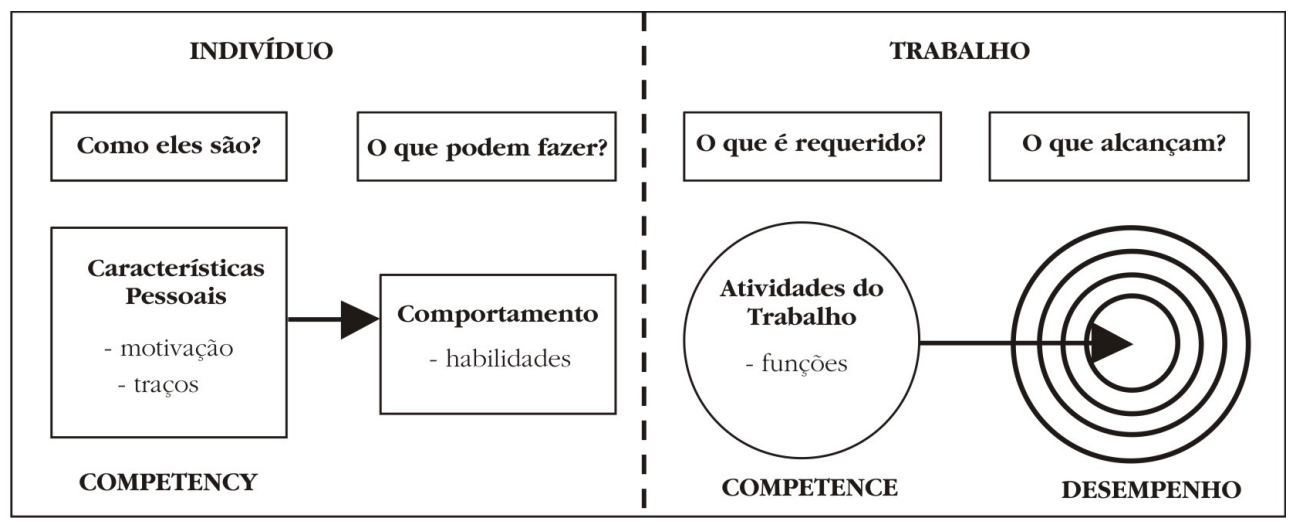

Fonte: Adaptado de Young; Dulewicz (2005).

Figura1: Competency e competence para o desempenho 
no setor público é feita pelo recrutamento e seleção, pelo acesso aos recursos, pelo fechamento de contratos no mercado ou, ainda, pela busca de resultados. O conceito defendido pelas autoras também é o de Boyatzis (1982), ou seja, competências na qualidade de características comportamentais de um indivíduo, em relação direta com o cumprimento eficaz ou notório de um trabalho.

\section{Conclusões}

Mesmo que o termo competência no trabalho esteja em evidência (BRANDÃO; Borges-ANDrADE, 2007) e a discussão da produção científica brasileira sobre o tema seja recente (BRANDÃO, 2009), ainda há uma lacuna sobre a discussão do construto e sua aplicação no setor público, em especial no caso brasileiro, quando se trata da administração pública federal. A edição do Decreto $\mathrm{n}^{\circ}$ 5.707, de 23 de fevereiro de 2006, que instituiu a política e as diretrizes para o desenvolvimento de pessoal, sistematizou alguns conceitos da gestão por competências para a administração pública, entre os quais a adequação das competências requeridas dos servidores aos objetivos das instituições; porém se trata de um marco recente, cujos conceitos e modelos de implementação ainda não foram empregados pela maioria dos órgãos.

Ao apresentar os diversos conceitos sobre competências no trabalho, este estudo conclui que os documentos analisados remetem à convergência do conceito de competência, diante da complexidade e fragmentação teórica previamente constatadas na literatura. Tal convergência é expressa pelo conceito de competências enquanto conhecimentos, habilidades e atitudes expressas pelo desempenho profissional, dentro de determinado contexto organizacional; ainda que haja, no caso internacional, duas correntes explícitas: a perspectiva francesa e a inglesa, a primeira com foco nos atributos individuais e a segunda com foco no desempenho.

São ainda elementos comuns dos conceitos, conforme identificados por Carvalho e outros (2009): referem-se ao mundo do trabalho e suas definições pressupõem a análise do trabalho e de seus contextos; os elementos constituintes da maioria são conhecimentos, habilidades e atitudes; e imprevisibilidade e evento, indicando que, mesmo que os indivíduos disponham dos repertórios de conhecimentos, habilidades e atitudes esperadas, haverá trabalhos novos e inesperados.

Já a produção empírica analisada segue uma tendência diagnosticada por Brandão (2009): a) em grande parte, descreve competências ocupacionais ou profissionais; b) possue desenho survey; c) apresenta pluralidade quanto à natureza da pesquisa e utilização de métodos e técnicas para coleta e análise de dados; e d) é realizada principalmente no setor terciário da economia. No que se refere à abordagem teórica do construto, também converge para uma concepção integradora.

Em grande parte das pesquisas são realizados levantamentos transversais, nos quais todas as variáveis são medidas ao mesmo instante. Existe, portanto, uma lacuna na realização de experimentos ou pesquisas com levantamentos longitudinais. Há, igualmente, ausência de estudos que investiguem a relação entre o construto das competências no trabalho com outros construtos de comportamento organizacional, tais como: satisfação no trabalho, comprometimento organizacional ou motivação. O tema é frequentemente investigado juntamente com os conceitos de aprendizagem e desempenho. Confirmado por Brandão (2009), 
poucos estudos investigam variáveis contextuais que poderiam influenciar a expressão de competências no trabalho.

$\mathrm{Na}$ análise da produção nacional, não foram encontrados relatos de pesquisa ou ensaios sobre segmentos da administração pública federal, compreendida enquanto segmento profissional dos servidores públicos dos ministérios, autarquias e fundações. Assim, sugere-se a lacuna de discussão do construto das competências no trabalho e também a carência de pesquisas empíricas nesse segmento.

Desta forma, ainda que a abordagem da competência esteja relativamente consolidada enquanto novo modelo para a gestão de pessoas, principalmente no setor privado e em segmentos específicos do setor público (como empresas públicas e sociedades de economia mista), na administração pública federal o tema e as decorrências de sua aceitação ainda são incipientes.

Convém observar que uma análise mais profunda sobre os problemas e os obstáculos enfrentados para a implantação da gestão por competências só pode ser feita a partir de um olhar mais apurado sobre a estrutura e a função das áreas de recursos humanos nos órgãos da administração pública.

(Artigo recebido em março de 2011. Versão final em dezembro de 2011).

\section{Referências bibliográficas}

Amaral, Mirian Maia do. Navegando nas ondas da educação on-line: competências do designer educativo. Revista de Administração Pública - RAP, Rio de Janeiro, FGV, v. 43, n. 6, p. 1487-1519, nov./dez. 2009.

Amaro, Rubens de Araújo. Da qualificação à competência: deslocamento conceitual e individualização do trabalhador. Revista de Administração Mackenzie - RAM, v. 9, n. 7, p. 89-11, 2008.

Appel, Heitor; Bittencourt, Cláudia Cristina. Gestão de pessoas por competências: institucionalização, possibilidades e dificuldades implícitas nas relações trabalhistas brasileiras. Revista Organização e Sociedade - O\&S, v. 15, n. 46, p. 175-193, jul./a set. 2008.

Bahry, Carla Patrícia; Tolfo, Suzana da Rosa. Mobilização de competências nas atividades profissionais dos egressos de um programa de formação e aperfeiçoamento. Revista de Administração Pública - RAP, Rio de Janeiro, v. 41, n. 1, p. 125-144, jan./fev. 2007.

Bнатта, Gambhir. Competencies, presicion, targeting, and senior management development. Public Sector, v. 24, n. 3, p. 16-20, 2001.

. Enabling the cream to rise to the top: a cross-jurisdictional comparison of competencies for senior managers in the public sector. Public Performance \& Management Review, v. 25, n. 2, p. 194-207, 2002.

Borges-Andrade, Jairo Eduardo; Meira, Maja. As pesquisas sobre comportamento organizacional no Brasil. In: CONGRESSO NORTE-NORDESTE DE PSICOLOGIA, 3, 2003, João Pessoa. Resumos... João Pessoa: Universidade Federal da Paraíba UFPB, v. 1, p. 386. 
Bourgault, Jacques. Stratégies et pratiques de dévelopment des compétences des cadres dans les organisations publiques. Revue Française d'Administration Publique, v. 116, n. 4, p. 609-622, 2005.

BOYATZIS, Richard E. The competent manager: a model for effective performance. New York: John Wiley \& Sons, 1982.

Brandão, Hugo Pena. Aprendizagem, Contexto, Desempenho e Competência: um Estudo Multinivel. 2009. Tese (Doutorado em Psicologia Social do Trabalho e das Organizações). Programa de Pós-Graduação em Psicologia Social do Trabalho e das Organizações - PGPSTO, Universidade de Brasília, Brasília.

Brandão, Hugo Pena; Bahry, Carla Patrícia; Freitas, Isa Aparecida. Os impactos do suporte à transferência sobre a aplicação de competências no trabalho: a percepção dos mestres e doutores do Banco do Brasil. Revista de Administração da Universidade de São Paulo-RAUSP, São Paulo, v. 43, n. 3, p. 224-237, jul./set. 2008.

Brandão, Hugo Pena; Borges-Andrade, Jairo Eduardo. Causas e efeitos da expressão competências no trabalho: para entender melhor a noção de competência. Revista de Administração Mackenzie - RAM, v. 8, n. 3, p. 32-49, 2007.

Brandão, Hugo Pena; Guimarães ,Tomás de Aquino. Gestão de competências e gestão de desempenho: tecnologias distintas ou instrumentos de um mesmo constructo? Revista de Administração de Empresas, São Paulo, v. 41, n.1, p. 8-15, jan./mar. 2001.

Brandão, Hugo Pena; Guimarães, Tomás de Aquino; Borges-Andrade, Jairo Eduardo. Competências profissionais relevantes à qualidade no atendimento bancário. Revista de Administração Pública, Rio de Janeiro, v. 35, n. 6, p. 61-81, nov./dez. 2001.

Brandão, Hugo Pena et. al. Gestão de desempenho por competências: integrando a gestão por competências, o balanced scorecard e a avaliação 360 graus. Revista de Administração Pública - RAP, Rio de Janeiro, FGV, v. 42, n. 5, p. 875-898, set./out. 2008.

BrasiL. Decreto $n^{\circ} 5.707$, de 23 de fevereiro de 2006. Institui a política e as diretrizes para o desenvolvimento de pessoal da administração pública federal direta, autárquica e fundacional, e regulamenta dispositivos da Lei no 8.112, de 11 de dezembro de 1990. Diário Oficial (da) República Federativa do Brasil, Brasília, DF, 24 fevereiro de 2006. Disponível em: http://www.planalto.gov.br/ccivil/_Ato2004-2006/2006/decreto/D5707.htm. Acesso em: 20 fev. 2011.

Bruno-Faria, Maria de Fátima; Brandão, Hugo Pena. Gestão de competências: identificação de competências relevantes a profissionais da área de T\&D de uma organização pública do Distrito Federal. Revista de Administração Contemporânea, Rio de Janeiro, v. 7, n. 3, p. 35-56, jul./set. 2003.

Campos, Keli Cristina de Lara et. al. Empregabilidade e competências: uma análise de universitários sob a ótica de gestores de recursos humanos. Revista Psicologia, Organizações e Trabalho - rPOT, Brasília, v. 8 , n. 2, p. 159-183, jul./dez. 2008.

CArdoso, Ricardo Lopes; Riccio, Edson Luiz; Albuquerque, Lindolfo Galvão. Competências do contador: um estudo sobre a existência de uma estrutura de interdependência. Revista de Administração da Universidade de São Paulo - RAUSP, São Paulo, v. 44, n. 4, p. 365-379, out./dez. 2009. 
Carvalho, Antônio Ivo de et al. Escolas de governo e gestão por competências: mesa redonda de pesquisa-ação. Brasília: ENAP, 2009.

Cassandre, Márcio Pascoal; Endrichi, José Otávio Montanha; Vercesi, Cristiane. Gestão por competências nas pequenas empresas do APL de bonés da cidade de Apucarana (PR): seu entendimento e suas práticas em confronto com as perspectivas teóricas. Revista de Administração Mackenżie - RAM, v. 9, n. 8, p.15-38, nov./dez. 2008.

De Sordi, José Osvaldo; Azevedo, Márcia Carvalho de. Avaliação de competências requeridas aos trabalhadores da informação: análise da experiência com a seleção de aluno para programa de iniciação científica. Revista de Administração da Universidade de São Paulo - RAUSP, São Paulo, v. 43, n. 4, p. 301-314, out./dez. 2008.

De Sordi, José Osvaldo et. al. Competências críticas ao desenvolvimento de mapas cognitivos de redes interorganizacionais. Revista de Administração Pública $-\mathrm{R} A P$, Rio de Janeiro, FGV, v. 43, n. 5, p. 1181-1206, set./out. 2009.

Di PIetro, Maria Sylvia Zanella. Direito Administrativo. São Paulo: Atlas, 2002.

Faria, Ligia Pirela; Alizo, Leticia Preito de. Perfil de competencias del docente en la función de investigador y su relación con la producción intelectual. Opción, v. 22, n. 50, p. 159-177, ago. 2006.

Farnham, David; Stevens, Amanda. Developing and implementing competence based recruitment and selection in a social services department - a case study of West Sussx Countil Council. The International Journal of Public Sector Management, v. 13, n. 4, p. 369382, 2000.

Gretha-TAYLOR, Heather. Identifying Collaborative Competencies. Review of Public Personnel Administration, v. 28, n. 2, p. 103-119, jun. 2008.

Hondeghem, Annie; Horton, Sylvia; Scheepers, Sarah. Modelos de gestão por competências na Europa. Revista do Serviço Público, v. 57, n. 2, p. 241-258, abr./jun. 2006.

Hondeghem, Annie; Vandermuelen, Filip. Competency management in the Flemish and Dutch civil service. The International Journal of Public Sector Management, v. 13, n. 4, p. 342-353, 2000.

HORTON, Sylvia. Introduction - the competency movement - its origins and impact on the public sector. The International Journal of Public Sector Management, v. 13, n. 4, p. 306-318, 2000. Le Boterf, Guy. Competénce et navigation profissionnelle. Paris: Éditions d'Organisation, 1999. Mello, Sérgio C. Benício de; FonsÊCA, Francisco Ricardo Bezerra; PAIVA JúnIor, Fernando Gomes de. Competências empreendedoras do dirigente de uma empresa de base tecnológica: um caso empresarial de sucesso. Revista de Administração Mackenzie - RAM, v. 8, n. 3, p. 50-76, 2007.

Miranda, Silvânia Vieira de. Necessidades de informação e competências informacionais no setor público: um estudo de caso. Revista do Serviço Público, Brasília, ENAP, v. 59, n. 1, p. 61-80, jan./mar. 2008.

Nalbandian, Carol; Nalbandian, Jonh. Meeting today's challenges: competencies for the contemporary local government professional. PM Public Management, v. 85, n. 4, p. 11-15, maio 2003. 
NAnquin, Sharon S.; Holton, Elwood. F. Leadership and managerial competency models: a simplified process and resulting model. Advances in Developing Human Resources, v. 8, n. 2, p. 144-165, 2006.

Noraida, Marcano; Mineira, Finol de Franco. Competencias personales y gerenciales de los directores y subdirectores de las escuelas básicas. Revista Venezoelana de Gerencia, Maracaibo, v. 12, n. 39, p. 410-430, set. 2007.

Perrenoud, Philippe. Construir as competências desde a escola. Porto Alegre: Artmed, 1999.

Ribeiro, Lore Margarete Manica; Guimarães, Tomás de Aquino; SouzA, Eda Castro Lucas de. Remuneração por competências: o ponto de vista de gestores de uma organização financeira estatal. Revista de Administração Mackenzie - RAM, v. 4, n. 2, p. 135-154, 2002.

Sant'Anna, Anderson Souza. Profissionais mais competentes: políticas de recursos humanos mais avançadas? Revista de Administração de Empresas - $\mathrm{R}$ AE eletrônica, São Paulo, FGV, v. 7, n.1, jan./jun. 2008.

Saupe, Rosita et. al. Avaliação das competências dos recursos humanos para a consolidação do Sistema Único de Saúde no Brasil. Texto \& Contexto Enfermagem, Florianópolis, v. 16, n. 4, p. 654-661, out./dez. 2007.

Sonnentag, Sabine; Frese, Michael. Performance concepts and performance theory. In: Sonnentag, S. (Ed.). Psychological Management of Individual Performance. Great Britain: John Wiley \& Sons Ltda, 2002.

VIRTANEn, Turo. Changing competences of public managers - tensions in commitment. The International Journal of Public Sector Management, v. 13, n. 4, p. 333-341, 2000.

Young, Mike; Dulewicz, Victor. A model of command, leadership and management competency in the British Royal Navy. Leadership \& Organization Development Journal, v. 26, n. 3, p. 228-241, 2003.

Zarifian, Philippe. Objetivo Competência: por uma nova lógica. Tradução Maria Helena C. V. Trylinski. São Paulo: Atlas, 2001. 


\section{Resumo - Resumen - Abstract}

\section{Conhecimentos, habilidades e atitudes: o conceito de competências no trabalho e seu uso no setor público \\ Aleksandra Pereira dos Santos}

Este estudo tem dois objetivos: revisar criticamente a produção científica nacional sobre o tema "competências no trabalho e nas organizações"; e apresentar o conceito e discutir sua utilização no setor público. Para tanto foram analisados relatos de pesquisa empírica e ensaios nacionais e estrangeiros - em periódicos de psicologia e administração. Foram discutidos: enfoques teóricos, instrumentos de coleta de dados, procedimentos de análise, entre outros aspectos. $\mathrm{Na}$ análise da produção nacional, constatou-se que, em sua maioria, as pesquisas: descrevem competências ocupacionais ou profissionais; possuem desenho survey; apresentam pluralidade quanto à natureza da pesquisa e utilização de métodos e técnicas para coleta e análise de dados; e são realizadas principalmente no setor terciário da economia. Verificou-se, ainda, a convergência do conceito de competência, diante da complexidade e fragmentação teórica previamente constatadas na literatura. Entretanto, mesmo em evidência, a produção científica brasileira sobre o tema é recente e ainda há uma lacuna sobre a discussão do construto e sua aplicação no setor público, em especial no caso brasileiro, quando se trata da administração pública federal, direta, autárquica e fundacional.

Palavras-chave: competências no trabalho e nas organizações, setor público, produção empírica nacional.

Conocimientos, habilidades e actitudes: el concepto de competencias en el trabajo y su uso en el sector público

Aleksandra Pereira dos Santos

Este estudio tiene dos objetivos: revisar críticamente la literatura científica sobre el tema de las competencias en el trabajo y en las organizaciones, y examinar el concepto y su uso en el sector público. Por lo tanto, se analizaron los informes de investigación empírica y ensayos nacionales y extranjeros - en revistas de psicología y de gestión. Se discutieron: enfoques teóricos, los instrumentos de recolección de datos, procedimientos de análisis, entre otros. En el análisis de la producción nacional, se observó que, en la mayoría de los casos, las investigaciones: describen las habilidades laborales o profesionales; tienen un dibujo survey; tienen una pluralidad de la naturaleza de la investigación y el uso de métodos y técnicas para la recogida y análisis de los datos; d) se llevan a cabo principalmente en el sector terciario de la economía. Hubo también la convergencia de la noción de competencia, dada la complejidad y la fragmentación teórica señaladas anteriormente en la literatura. Sin embargo, aún en pruebas, la literatura científica nacional sobre el tema es reciente y todavía existe una brecha en la discusión de la construcción y su aplicación en el sector público, especialmente en Brasil, cuando se trata de la administración pública (directa e indirecta).

Palabras clave: competencias en el trabajo y en las organizaciones, el sector público, la producción nacional empírica. 
Knowledge, skills and attitudes: the concept of competencies at work and its use in the public sector

Aleksandra Pereira dos Santos

This study has two objectives: to make a critical review of the scientific literature about competencies at work and in organizations and examine its concept and use in the public sector. Therefore, we analyzed empirical research reports and essays - national and foreign - in journals of psychology and business administration. The following were observed: theoretical approaches, data collection instruments, analysis procedures, and so forth. In the analysis of the national production, it was found that, in most cases, the researches: describe occupational or professional skills; have a survey drawing; bear some plurality about the nature of research and the use of methods and techniques for collecting and analyzing data; and are performed mainly in the tertiary sector of the economy. There was also a convergence in the concept of competence, given the complexity and theoretical fragmentation noted previously in the literature. However, despite of the importance of the theme, the Brazilian scientific literature on the topic is still recent and presents a gap in the discussion about its concept and application in the public sector, especially in Brazil, considering its federal model of government.

Keywords: competencies at work and in organizations, public sector, national production, empirical research.

Doutoranda em Psicologia Social, do Trabalho e das Organizações, na Universidade de Brasília. Mestre em Ciências da Informação (Universidade de Brasília) e graduada em Comunicação Social (Universidade Federal do Piauí). É Especialista em Políticas Públicas e Gestão Governamental, lotada no Ministério do Planejamento, Orçamento e Gestão. Contato: aleksandrapds@gmail.com 